\title{
Texture Classification Based on Texton Features
}

\author{
U Ravi Babu \\ Research Scholar, Aacharya Nagarjuna University \\ Asst. Professor - GIET Rajahmundry, A.P, India \\ uppu.ravibabu@gmail.com \\ V Vijay Kumar \\ Dean,Dept. of Comp.Sciences \\ Head, SRRF- G.I.E.T, Rajahmundry, A.P, India \\ vakulabharanam@hotmail.com \\ B Sujatha \\ Assoc. Professor., Dept. of CSE, \\ GIET Rajahmundry, A.P, INDIA \\ birudusujatha@gmail.com
}

\begin{abstract}
Texture Analysis plays an important role in the interpretation, understanding and recognition of terrain, biomedical or microscopic images. To achieve high accuracy in classification the present paper proposes a new method on textons. Each texture analysis method depends upon how the selected texture features characterizes image. Whenever a new texture feature is derived it is tested whether it precisely classifies the textures. Here not only the texture features are important but also the way in which they are applied is also important and significant for a crucial, precise and accurate texture classification and analysis. The present paper proposes a new method on textons, for an efficient rotationally invariant texture classification. The proposed Texton Features (TF) evaluates the relationship between the values of neighboring pixels. The proposed classification algorithm evaluates the histogram based techniques on TF for a precise classification. The experimental results on various stone textures indicate the efficacy of the proposed method when compared to other methods.
\end{abstract}

Index Terms - Texture image, Texton pattern, Classification

\section{INTRODUCTION}

Texture is regarded as a "fuzzy" concept with no mathematical or comprehensive definition agreed upon yet. The term of texture is a somewhat misleading term in computer vision, which is not the normal meaning of the word. One can recognize textures but it is very difficult to describe. There is no unique and precise definition of texture. Some texture features classifies precisely the textures based on a specific method, where as the same texture features may fail in classifying the objects based on a different method.

Textures characteristic intensity (or color) variations typically originate from roughness of object surfaces. There is simply no singly accepted definition for texture
$[1,2]$. Originally the term 'texture' is adopted from textiles, where it refers to the weave of various threads loose or tight, even or mixed [3]. It intrinsically provides structural information to the interpreter, in the form of the spatial arrangement of objects, region discrimination, surface orientation, and shape in 2 and 3-D environments $[4,5,6,7]$.

Classification refers to as assigning a physical texture object or incident into one of a set of predefined categories. Texture classification assigns a given texture to some texture classes [8, 9, 10, 11, 12, 13, 14, 15]. Two main classification methods are supervised and unsupervised classification. Supervised classification is provided examples of each texture class as a training set. A supervised classification is trained using the set to learn a characterization for each texture class. Unsupervised classification does not require prior knowledge, which is able to automatically discover different classes from input textures. Another class is semi-supervised with only partial prior knowledge being available.

Study of patterns on textures is recognized as an important step in characterization and classification of texture. Various approaches are existing to investigate the textural and spatial structural characteristics of image data, including measures of texture [16], Fourier analysis [17], fractal dimension [18], variograms [1, 19, 20, 21] and local variance measures [22]. Fourier analysis is found as the most useful when dealing with regular patterns within image data. It has been used to filter out speckle in radar data [23] and to remove the effects of regular agricultural patterns in image data [23]. Study of regular patterns based on fundamentals of local variance was carried out recently [24]. Various pattern based texture classification methods are proposed using wavelets [25, 26, 27]. These wavelet based methods classified the textures precisely. Good texture classification results are obtained using simple patterns and long linear patterns [28, 29, 30]. Texture 
classification methods based on texture units and spectrum also resulted a good classification [ 31, 32 ]. But the main disadvantages of some of these methods are the high range of texture unit numbers. Recently Stone Texture Classification Based on Primitive Pattern Units (PPU) [33] is also studied. These Primitive Pattern Units evaluate a new method of classification of stone textures based on frequency of occurrences of PPU's with surrounding grain components on a $3 \times 3$ mask. Good texture classification results are obtained using PPU. Based on the assumption that the regular textures are composed of several patterns, the present study attempted to classify various stone textures based on texton pattern trends, which is different from the earlier studies. In this work, classification accuracy can refer to the percentage of correctly classified texture samples.

The rest of the paper is organised as follows. Section 2 describes texton feature evaluation method. Experimental results and comparison the results with other methods are discussed in section 3 and conclusions are given in section 4.

\section{TEXTON FEATURE EVALUATION METHOD}

Various algorithms are proposed by many researchers to extract color, texture and other features. Color is the most distinguishing important and dominant visual feature. That's why color histogram techniques remain popular in the literature. The main drawback of this is, it lacks spatial information. Texture patterns can provide significant and abundance of texture and shape information. One of the features proposed by Julesz [25] called texton, represents the various patterns of image which is useful in texture analysis. The proposed method consists of four steps which are listed below. In the first step of the proposed TF evaluation, the color image is converted in to grey level image by using any color quantization method. The present paper used RGB color quantization method as described below.

\section{Step 1: Color Quantization of 7-bit Binary Code}

During the course of feature extraction, the original images are quantized into 128 colors of RGB color space and the color gradient is computed from the RGB color space and then the statistical information of textons is calculated to describe image features.

In order to extract gray level features from color information, the proposed T\&TO-CM utilized the RGB color space which quantizes the color space into 7-bins to obtain 128 gray levels. The index matrix of 128 color image is denoted as $\mathrm{C}(\mathrm{x}, \mathrm{y})$. The $\mathrm{RGB}$ quantization process is done by using 7-bit binary code of 128 colors as given in Eqn.(1).

$\mathrm{C}(\mathrm{x}, \mathrm{y})=16 * \mathrm{I}(\mathrm{R})+2 * \mathrm{I}(\mathrm{G})+\mathrm{I}(\mathrm{B})$

where

$$
\begin{array}{r}
\mathrm{I}(\mathrm{R})=0,0 \leq \mathrm{R} \leq 16, \quad \mathrm{I}(\mathrm{R})=\mathrm{i},\left(\left(16^{*} \mathrm{i}\right)+1\right) \leq \mathrm{R} \leq\left(16^{*}(\mathrm{i}+1)\right) \\
\mathrm{i}=[1,2, \ldots, 7]
\end{array}
$$

$$
\begin{array}{cc}
\mathrm{I}(\mathrm{G})=0,0 \leq \mathrm{G} \leq 16, & \mathrm{I}(\mathrm{G})=\mathrm{i},\left(\left(16^{*} \mathrm{i}\right)+1\right) \leq \mathrm{G} \leq\left(16^{*}(\mathrm{i}+1)\right) \\
\mathrm{i}=[1,2, \ldots, 6] & \\
\mathrm{I}(\mathrm{B})=0,0 \leq \mathrm{B} \leq 32, & \mathrm{I}(\mathrm{B})=\mathrm{i},((32 * \mathrm{i})+1) \leq \mathrm{B} \leq(32 *(\mathrm{i}+1)) \\
\mathrm{i}=[1,2,3]
\end{array}
$$

Therefore, each value of $\mathrm{C}(\mathrm{x}, \mathrm{y})$ is a 7 bit binary code ranging from 0 to 127.

\section{Step 2: Texton detection}

Textons [34, 35] are considered as texture primitives, which are located with certain placement rules. A close relationship can be obtained with image features such as shape, pattern, local distribution orientation, spatial distribution, etc.., using textons. The textons are defined as a set of blobs or emergent patterns sharing a common property all over the image $[34,35]$. The different textons may form various image features. To have a precise and accurate texture classification, the present study strongly believes that one need to consider all different textons. That is the reason the present study considered all. There are several issues related with i) texton size ii) tonal difference between the size of neighbouring pixels iii) texton categories iv) expansion of textons in one orientation v) elongated elements of textons with jittered in orientation. By this some times a fine or coarse or an obvious shape may results or a pre-attentive discrimination is reduced or texton gradients at the texture boundaries may be increased. To address this, the present paper utilized four texton types on a $2 \times 2$ grid as shown in figure 1(a). In figure 1(a), the four pixels of a $2 \times 2$ grid are denoted as $\mathrm{V}_{1}, \mathrm{~V}_{2}, \mathrm{~V}_{3}$ and $\mathrm{V}_{4}$. If two pixels are highlighted in gray color of same value then the grid will form a texton. The six texton types denoted as $\mathrm{TP}_{1}, \mathrm{TP}_{2}, \mathrm{TP}_{3}, \mathrm{TP}_{4}$, $\mathrm{TP}_{5}$ and $\mathrm{TP}_{6}$ are shown in figure 1(b) to 1(e). The working mechanism of texton detection for the proposed method is illustrated in figure 2.

Step 3: once the textons are identified, the present paper evaluated the frequency of occurrences of all six different textons as shown in Figure1 with different orientations. To have a precise and accurate texture classification, the present study considered sum of the frequencies of occurrences of all six different textons as shown in Figure 1 on a $2 \times 2$ block.

Step 4: In step four the sum of frequency of occurrences of blob texton patterns are evaluated. The blob texton pattern and working mechanism is shown in figure 3 and figure 4 respectively.

\begin{tabular}{|l|l|}
\hline V1 & V2 \\
\hline V3 & V4 \\
\hline
\end{tabular}

(a)

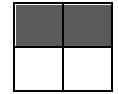

(b)

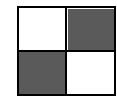

(c)

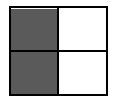

(d)

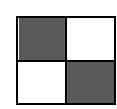

(e)

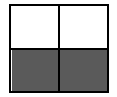

(f)

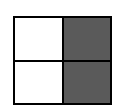

(g) figure 1 Six special types of Textons: a) $2 \times 2$ grid b) $\mathrm{TP}_{1}$ c) $\mathrm{TP}_{2}$ d) $\mathrm{TP}_{3}$ e) $\mathrm{TP}_{4}$ f) $\mathrm{TP}_{5}$ and g) $\mathrm{TP}_{6}$. 


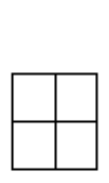

(a)

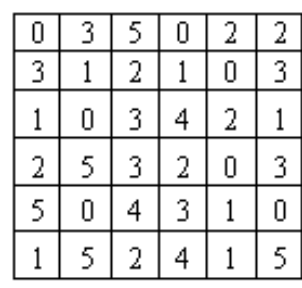

(b)

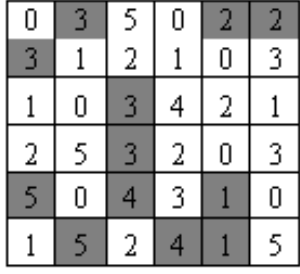

(c)

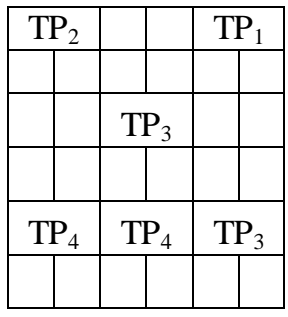

(d)

\begin{tabular}{|l|l|l|l|l|l|}
\hline 0 & 3 & 0 & 0 & 2 & 2 \\
\hline 3 & 1 & 0 & 0 & 0 & 3 \\
\hline 0 & 0 & 3 & 4 & 0 & 0 \\
\hline 0 & 0 & 3 & 2 & 0 & 0 \\
\hline 5 & 0 & 4 & 3 & 1 & 0 \\
\hline 1 & 5 & 2 & 4 & 1 & 5 \\
\hline
\end{tabular}

(e) figure 2 Illustration of the texton pattern detection process: (a) $2 \times 2$ grid (b) Original image (c) \& (d) Texton location and texton types (e) Texton image.

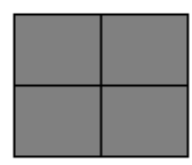

figure $32 \times 2$ Texton pattern blob.

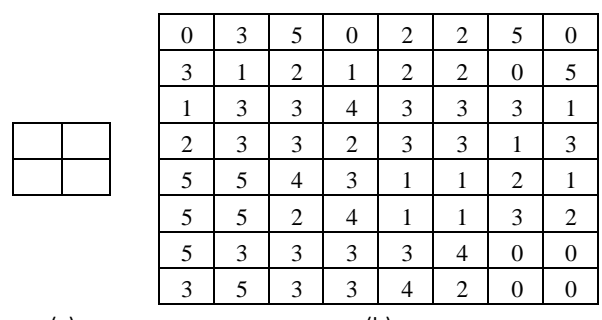

(a)

(b)

\begin{tabular}{|l|l|l|l|l|l|l|l|}
\hline 0 & 3 & 5 & 0 & 2 & 2 & 5 & 0 \\
\hline 3 & 1 & 2 & 1 & 2 & 2 & 0 & 5 \\
\hline 1 & 3 & 3 & 4 & 3 & 3 & 3 & 1 \\
\hline 2 & 3 & 3 & 2 & 3 & 3 & 1 & 3 \\
\hline 5 & 5 & 4 & 3 & 2 & 1 & 2 & 2 \\
\hline 5 & 5 & 2 & 4 & 1 & 3 & 2 & 2 \\
\hline 5 & 3 & 3 & 3 & 3 & 4 & 0 & 0 \\
\hline 3 & 5 & 3 & 3 & 4 & 2 & 0 & 0 \\
\hline 0
\end{tabular}$\quad$\begin{tabular}{|l|l|l|l|l|l|l|l|}
0 & 0 & 0 & 0 & 2 & 2 & 0 & 0 \\
\hline 0 & 0 & 0 & 0 & 2 & 2 & 0 & 0 \\
\hline 0 & 0 & 0 & 0 & 3 & 3 & 0 & 0 \\
\hline 0 & 0 & 0 & 0 & 3 & 3 & 0 & 0 \\
\hline 5 & 5 & 0 & 0 & 0 & 0 & 2 & 2 \\
\hline 5 & 5 & 0 & 0 & 0 & 0 & 2 & 2 \\
\hline 0 & 0 & 3 & 3 & 0 & 0 & 0 & 0 \\
\hline 0 & 0 & 3 & 3 & 0 & 0 & 0 & 0 \\
\hline
\end{tabular}

figure 4 Illustration of the texton pattern detection process: (a) $2 \times 2$ grid (b) Original image (c) Texton location (d) Texton image

\section{RESULTS AND DISCUSSIONS}

The present paper carried out the experiments on various Brick, Granite, Marble and Mosaic textures each of size $256 \times 256$ collected from Brodatz textures, Vistex and also from natural resources from digital camera. Some of them are shown in Figure 5.

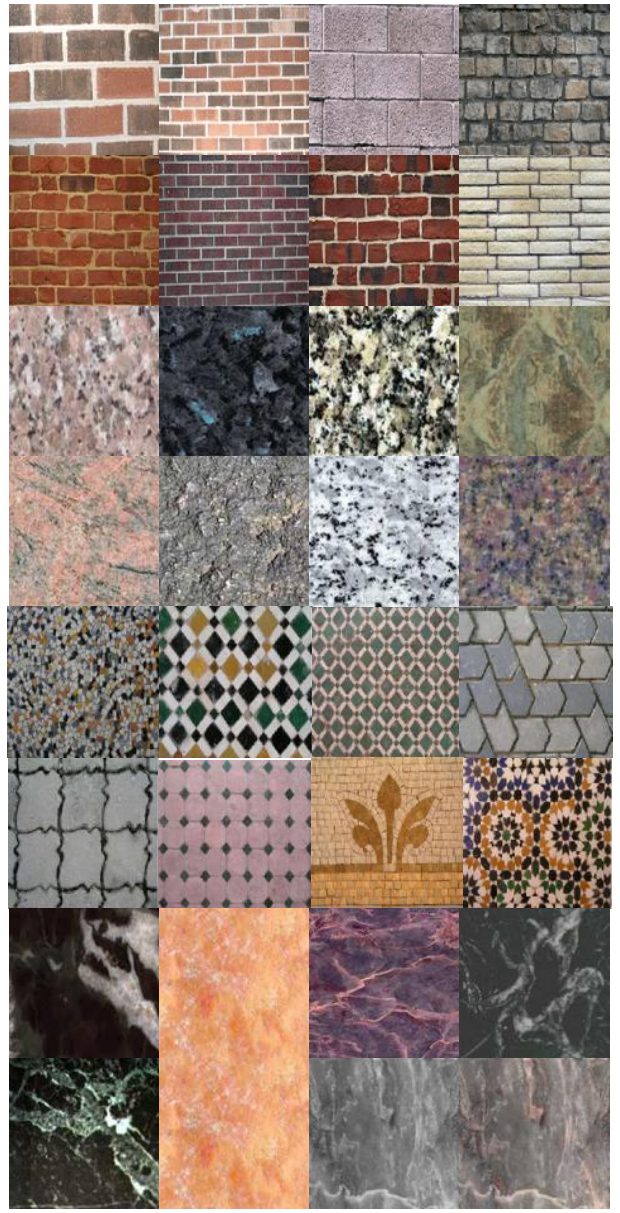

figure 5 Input texture group of 8 samples of Brick, Granite, Marble, Mosaic

TABLE 1 . FREQUENCY OCCURANCE OF 2 X 2 TEXTTON PATTERNS FOR 4 CATAGORIES OF STONE TEXTURES

\begin{tabular}{|c|c|c|c|c|}
\hline $\begin{array}{c}\text { Stone } \\
\text { Number }\end{array}$ & Brick & Granite & Marble & Mosaic \\
\hline 1 & 9978 & 2268 & 5819 & 378 \\
\hline 2 & 11698 & 1807 & 7248 & 141 \\
\hline 3 & 11528 & 1987 & 4310 & 394 \\
\hline 4 & 13557 & 2084 & 5507 & 235 \\
\hline 5 & 13151 & 2338 & 5576 & 234 \\
\hline 6 & 10891 & 2408 & 8543 & 179 \\
\hline 7 & 10581 & 1904 & 6140 & 220 \\
\hline 8 & 11585 & 1491 & 4953 & 169 \\
\hline 9 & 12081 & 1599 & 7735 & 406 \\
\hline 10 & 10811 & 2696 & 8414 & 216 \\
\hline 11 & 11334 & 2338 & 4024 & 919 \\
\hline 12 & 12657 & 2889 & 8334 & 858 \\
\hline 13 & 11969 & 1799 & 8161 & 382 \\
\hline 14 & 13272 & 2241 & 3428 & 261 \\
\hline & & & & \\
\hline 1 & & & & \\
\hline
\end{tabular}


The sum of frequency of occurrence of six texton patterns of each input texture image is listed out in Table I. The Table 1 and the classification graph of Figure6, indicates a precise and accurate classification of the considered stone textures.

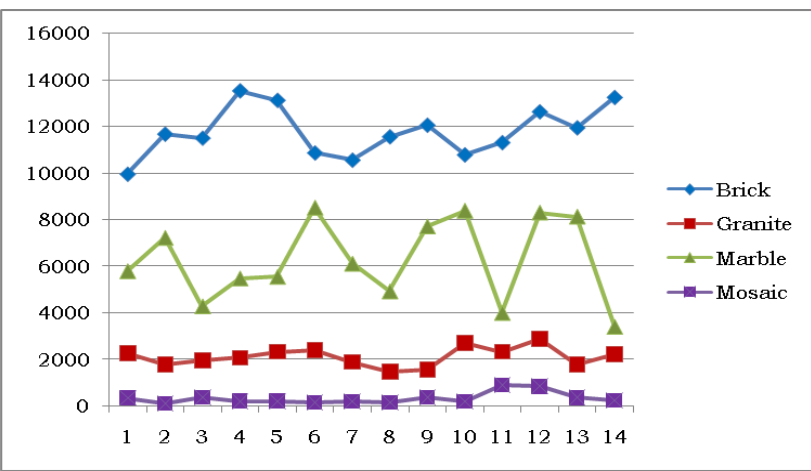

figure 6 Classification graph of stone textures based on sum of the occurences of TF.

The frequency of occurrence of blob texton features are listed in Table 2. The plotted graph of the Fig 7 based on table 2 only shows a precise classification of brick textures, because of this high range of occurring frequency of blobs on IT texton images. The classification of other three stone textures is not visible in Fig 7. To overcome this visibility problem a graph is only drawn by normalizing the values by dividing by 10 , for the three stone textures namely granite, marble and mosaic of table 2 as shown in Fig 8 . The Fig 8 clearly indicates a precise and accurate classification of the considered stone textures.

TABLE 2 FREQUENCY OCCURANCE OF 2 X 2 TEXTTON BLOB FOR 4 CATAGORIES OF STONE TEXTURES

\begin{tabular}{|c|c|c|c|c|}
\hline $\begin{array}{c}\text { Stone } \\
\text { Number }\end{array}$ & Brick & Granite & Marble & Mosaic \\
\hline 1 & 6896 & 48 & 272 & 0 \\
\hline 2 & 9956 & 32 & 84 & 0 \\
\hline 3 & 9376 & 20 & 936 & 0 \\
\hline 4 & 15888 & 12 & 408 & 0 \\
\hline 5 & 12812 & 28 & 192 & 0 \\
\hline 6 & 8340 & 24 & 156 & 0 \\
\hline 7 & 8096 & 60 & 2412 & 0 \\
\hline 8 & 8992 & 12 & 676 & 0 \\
\hline 9 & 11336 & 48 & 160 & 0 \\
\hline 10 & 7156 & 12 & 1312 & 0 \\
\hline 11 & 8388 & 16 & 84 & 0 \\
\hline 12 & 11960 & 16 & 836 & 0 \\
\hline 13 & 11324 & 24 & 80 & 0 \\
\hline 14 & 12520 & 8 & 545 & 0 \\
\hline 15 & 12796 & 12 & 321 & 0 \\
\hline
\end{tabular}

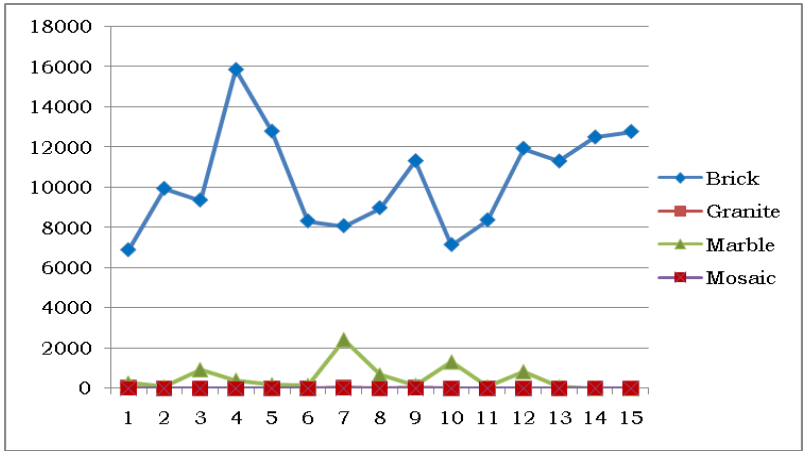

figure 7 Frequency of occurrence of blob texton patterns.

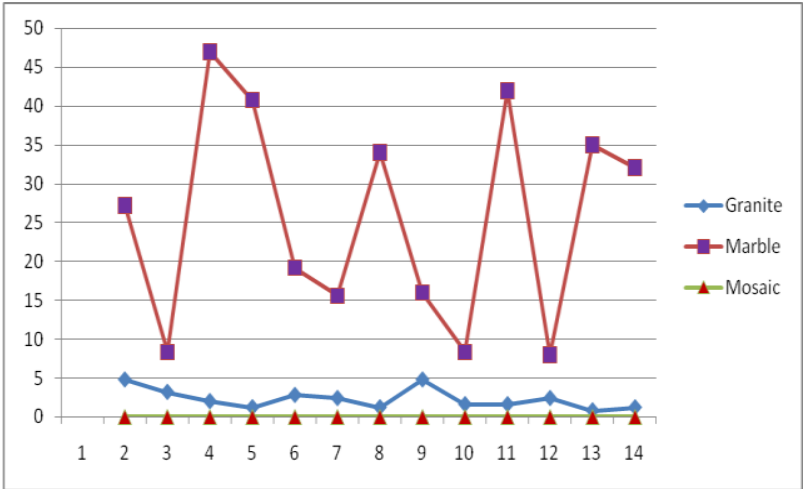

figure 8 Frequency of occurrence of blob texton patterns of Granite, Marble and Mosaic.

The proposed texton feature detection is compared with Syntactic Pattern on 3D method [36] and Primitive Pattern Unit approach [22] methods. The above methods classified stone textures into two groups only. This indicates that the existing methods[12, 27] failed in classifying all stone textures. Further the present paper evaluated mean classification rate using $k-n n$ classifier. The percentage of classification rates of the proposed method and crashes methods [7, 13] are listed in table 3. The table 3 clearly indicates that the proposed texton feature detection outperforms the other existing methods and did not need any classification technique. Figure9 shows the comparison chart of the proposed texton feature detection with the other existing methods of Table 3.

TABLE 3 MEAN \% CLASSIFICATION RATE OF THE PROPOSED AND EXISTING METHODS

\begin{tabular}{|c|c|c|c|}
\hline Image Dataset & $\begin{array}{c}\text { Syntactic } \\
\text { Pattern on } \\
\text { 3D method }\end{array}$ & $\begin{array}{c}\text { Primitive } \\
\text { Pattern Unit } \\
\text { approach }\end{array}$ & $\begin{array}{c}\text { Proposed } \\
\text { Texton Feature } \\
\text { Detection }\end{array}$ \\
\hline Akarmarble & 93.29 & 92.19 & 95.56 \\
\hline VisTex & 92.53 & 92.56 & 94.15 \\
\hline Ashishimpex & 93.30 & 91.29 & 95.27 \\
\hline Brodatz & 93.59 & 92.16 & 94.97 \\
\hline
\end{tabular}




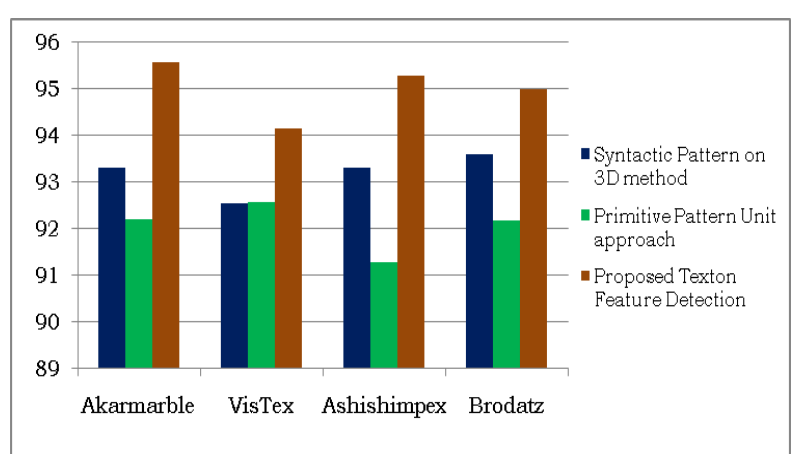

figure 9 Comparison graph of proposed and existing systems.

\section{CONCLUSIONS}

Textons are considered as texture primitives. The different textons may form various image features. Based on the texton features the present paper evaluated a classification feature which is rotationally invariant. The proposed TF evaluates the relationship between the values of neighboring pixels. The proposed classification algorithm evaluates the histogram based techniques on $\mathrm{TF}$ for a precise classification. The proposed method is computationally attractive as it computes different $\mathrm{TF}$ with limited number of selected pixels. The present paper proposed two methods to classify the textures among the class of textures based on Texton features. The graphs plotted based on occurrences of texton patterns clearly classifies and recognizes Brick, Marble, Granite and Mosaic textures precisely. The recent stone texture Classification methods failed in classifying all the stone textures precisely.

\section{ACKNOWLEDGMENT}

The authors would like to express their gratitude to Sri K.V.V. Satya Narayana Raju, Chairman, and K. Sashi Kiran Varma, Managing Director, Chaitanya group of Institutions for providing necessary infrastructure. Authors would like to thank anonymous reviewers for their valuable comments and Dr. G.V.S. Ananta Lakshmi for her invaluable suggestions which led to improvise the presentation quality of this paper.

\section{REFERENCES}

[1] D. A. Forsyth and J. Ponce. Computer Vision: A modern approach. Prentice Hall, 2002

[2] Eswar Reddy, B., Vijaya Kumar, V. et al. (2007). Texture Classification by Simple Edge Direction Movements. International Journal of Computer Science and Network Security, vol. 7, no.11, pp. 221-225

[3] G. Smith and I. Burns. Measuring texture classification algorithms. PRL, 18(14):1495-1501, December 1997.

[4] Fogel and D. Sagi. Gabor filters as texture discriminator. BioCyber, 61:102-113, 1989
[5] M. Varma. and A. Zisserman. Classifying images of materials: Achieving viewpoint and illumination independence. In ECCVO2, page III: 255 ff., 2002.

[6] R. Chellappa and S. Chatterjee. Classification of textures using gaussian markov random fields. ASSP, 33:959-963, August 1985

[7] T. K. Leung and J. Malik. Representing and recognizing the visual appearance of materials using three-dimensional textons. IJCV, 43(1):29-44, June 2001

[8] Atkinson, P. M. and Lewis, P. (2000). Geostatistical classification for remote sensing: An introduction. Comput. Geosci., Vol. 26, pp. 361-371

[9] J. Mao and A. K. Jain. Texture classification and segmentation using multiresolution simultaneous autoregressive models. Pattern Recogn., 25(2):173188,1992

[10] Klatzky, R.L., C. Reed and S. Lederman. 1987. There's More to Touch Than Meets the Eye: The Salience of Object Attributes for Haptics With and Without Vision. Journal of Experimental Psychology. General. Vol. 116, No. 4, pp. 356-69

[11] M. Varma. and A. Zisserman. Texture classification: are filter banks necessary? In CVPRO3, pages II: 691-698, 2003.

[12]Richards, J. A. and Xiuping, J. (1999). Remote SensingDigital Analysis: An Introduction. Germany: Springer-Verlag, Vol.3, pp.363-383.

[13]T. Ojala, M. Pietikainen, and D. Harwood. A comparative study of texture measures with classification based on feature distributions. Pattern Recognition, 29(1):51-59, January 1996

[14] Woodcock, C. E., Strahler, A. H. and Jupp, D. L. B. (1988). The use of variograms in remote sensing II: Real digital images, Remote Sens. Environ., Vol. 25, pp. 349-379

[15] Woodcock, C. E. and Strahler, A. H. (1987). The factor of scale in remote sensing. Remote Sens. Environ., Vol. 21, pp. 311-332

[16] Curran, P. J. (1988). The Semivariogram in Remote Sensing: An Introduction. Remote Sens. Environ., vol. 24, pp. 493-507

[17] Vijaya Kumar, V., Eswar Reddy, B., et al. (2008). Classification of Textures by Avoiding Complex Patterns. Journal of Com. Science, vol. 4(2), pp.133138

[18]A. S. Hornby, "Oxford Advanced Learner's Dictionary of Current English," 6 ed.: Oxford University Press, 2000

[19] Gibson, J.J. 1950. The Perception of Visual Surfaces. American Journal of Psychology. Vol. 63. pp. 367385 
[20] McCloy, K.R. (2002). Analysis and removal of the effects of crop management practices in remotely sensed images of agricultural fields. Int. J. Remote Sens., vol. 23, pp. 403-416.

[21] Vijaya Kumar, V., Eswar Reddy, B. et al. (2007). An Innovative Technique of Texture Classification and Comparision based on Long Linear Patterns. Journal of Computer Science, Science Publications, vol. 3(8), pp.633-638

[22] Suresh, A., U S N Raju and Vijaya Kumar, V. et al. (2010) An Innovative Technique of Stone Texture Classification Based on Primitive Pattern Units, Journal of Signal and Image Processing (Vol.12010/Iss. 1 pp. 40-45

[23] Moody, A. and Johnson, D. M. (2001). Land-surface phenologies from AVHRR using the discrete fourier transform. Remote Sens. Environ., Vol. 75, pp. 305323

[24] Burrough, P. A. (1983). Multiscale sources of spatial variation in soil, the application of fractal concepts to nested levels of soil variation. J. Soil Sci., Vol. 34, pp. $577-597$

[25] Julesz, B. and J.R. Bergen. 1983. Textons, the fundamental elements inpreattentive vision and perception of textures, Bell System Tech. J. 62, 1619-1646

[26]Peder, Klith Bocher. and Keith, R. McCloy. (2006). The Fundamentals of Average Local Variance: Detecting Regular Patterns. IEEE Trans. on Image Processing, vol. 15, pp. 300-310.

[27] Suresh, A., U S N Raju and Vijaya Kumar, V. et al. (2010) An Innovative Technique of Stone Texture Classification Based on Primitive Pattern Units, Journal of Signal and Image Processing (Vol.12010/Iss. 1 pp. 40-45

[28] Lederman, S.J., B. Jones and G. Thorne. 1986. Perception of Texture by Vision and Touch: Multidimensionality and Intersensory Integration. Journal of Experimental Psychology: Human Perception and Performance. Vol. 12, No. 2, pp. 169180.

[29] Vijaya Kumar, V., Raju, U.S.N. et al. (2009). Employing Long Linear Patterns for Texture Classification relying on Wavelets. International Journal of Graphics Vision and Image Processing, vol. 8, no. 5, pp. 13-21

[30] Vijaya Kumar, V., et al. (2008). A New Method of Texture Classification using Wavelet Transforms based on Primitive Patterns. International Journal of Graphics Vision and Image Processing, vol. 8, no. 2, pp. $21-27$

[31]B. Sujatha, Dr.V.VijayaKumar, M Chandramohan, "Rotationally Invariant Texture Classification using LRTM based on Fuzzy Approach”, International
Journal of Computer Applications (0975 - 8887) Volume 33-No.4, November 2011.

[32] B. Sujatha, Dr.V.VijayaKumar, Dr.P. Harini “A New Logical Compact LBP Co-Occurrence Matrix for Texture Analysis", International Journal of Scientific \& Engineering Research, Volume 3, Issue 2, February-2012

[33] Treitz, P. (2001). Variogram analysis of high spatial resolution remote sensing data: An examination of boreal forest ecosystems. Int. J. Remote Sens., vol. 22, pp. 3895-3900

[34]Julesz B., -Textons, The Elements of Texture Perception, and their Interac-tions," Nature, vol.290 (5802): pp.91-97, 1981.

[35] Julesz B., - Texton gradients: the texton theory revisited," Biological Cybernet-ics, vol.54 pp.245251,1986

[36] Suresh A and Vijaya Kumar V. et al., "Pattern Based Classification of Stone Textures on a Cubical Mask," International Journal of Universal Computer Sciences (Vol.1-2010/Iss.1) pp. 4-9

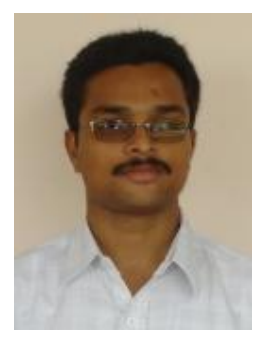

U Ravi Babu obtained his MSc Information Systems (IS) from AKRG PG College, Andhra University in the year 2003 and M.Tech Degree from RVD University in the year 2005. He is a member of SRRF-GIET, Rajahmundry. He is pursuing his Ph.D from AN University-Guntur in Computer Science \& Engineering under the guidance of Dr V. Vijaya Kumar. He has published research papers in various National, Inter National conferences, proceedings. He is working as an Assistant Professor in GIET, Rajahmundry from July 2003 to till date. He is a life member of ISCA

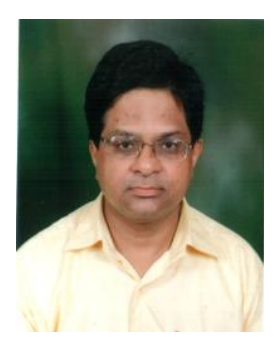

Vakulabharanam Vijaya Kumar received integrated M.S. Engg, degree from Tashkent Polytechnic Institute (USSR) in 1989. He received his Ph.D. degree in Computer Science from Jawaharlal Nehru Technological University (JNTU) in 1998.He has served the JNT University for 13 years as Assistant Professor and Associate Professor and taught courses for M.Tech students. He has been Dean for Dept of CSE and IT at Godavari Institute of Engineering and Technology since April, 2007.His research interests include Image Processing, Pattern Recognition, Network Security, Steganography, Digital Watermarking, and Image retrieval. He is a life member for CSI, ISTE, IE, IRS, ACS and CS. He has published more than 80 
research publications in various National, Inter National conferences, proceedings and Journals.

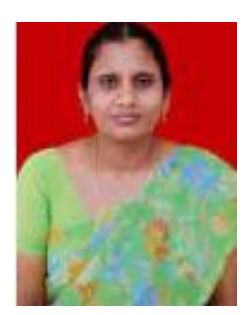

B.Sujatha received the B.Tech. degree from JNT University, Kakinada in 1997 and received her M. Tech. (Computer Science \& Engineering) from Andhra University in 2002. She is having 10 years of teaching experience. Presently she is working as an Assoc. Professor in GIET, Rajahmundary. She has published 15 research publications in Inter National Journal. She is a member of SRRF-GIET, Rajahmundry. She is pursuing her Ph.D from Mysore University in Computer Science under the guidance of Dr. V.Vijaya Kumar. Her research interest includes Image Processing and Pattern Recognition. She is a Life member of ISCA. 